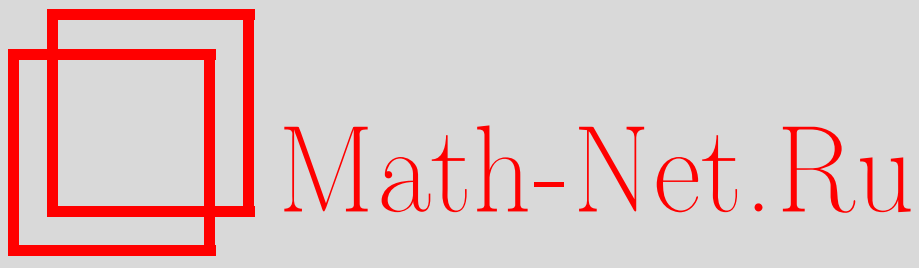

Г. Д. Гуреев, Д. М. Гуреев, Лазерное и лазерно-ультразвуковое упрочнение поверхности металлических пластин, Вестн. Сам. гос. техн. ун-та. Сер. Физ.-мат. науки, 2005, выпуск 34, 90-94

DOI: https://doi.org/10.14498/vsgtu342

Использование Общероссийского математического портала Math-Net.Ru подразумевает, что вы прочитали и согласны с пользовательским соглашением

http://www. mathnet.ru/rus/agreement

Параметры загрузки:

IP : 52.87 .193 .239

26 апреля 2023 г., 16:41:17

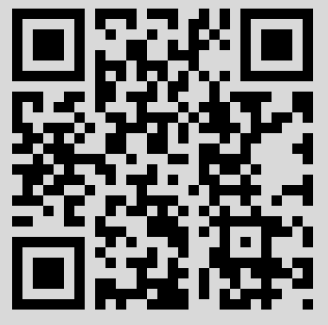


13. Гуляев Ю.В., Зильберман П.Е, Луговской А.В. Влияние неоднородного обмена и диссипации на распространение поверхностных волн Дэймона-Эшбаха в ферромагнитной пластине // ФТТ. 1981. Том 23.Вып. 4. C. $1136-1142$.

14. Вапнэ Г.М. СВЧ устройства на магнитостатических волнах // ЦНИИ Электроника. Обзоры по электронной технике. Сер.1. Электроника СВЧ. 1984. Вып. 8. 80 с.

Поступила 2.02.2005 2.

УДК 621.373 .826

Г.Д. Гуреев, Д.М. Гуреев

\title{
ЛАЗЕРНОЕ И ЛАЗЕРНО-УЛЬТРАЗВУКОВОЕ УПРОЧНЕНИЕ ПОВЕРХНОСТИ
} МЕТАЛЛИЧЕСКИХ ПЛАСТИН

\begin{abstract}
Экспериментально исследовано влияние толщчны металлической пластины на глубину зоны закалки ее поверхности непрерывным лазерным излучением. Из сопоставления экспериментальных результатов с теоретическими зависимостями, основанными на моделях полубесконечной среды, тонкой пластины и промежуточной модели, получено эмпирическое аналитическое соотношение, связывающее глубину зонь закалки с параметрами лазерного воздействия, теплофизическими характеристиками материала пластины и ее толщиной. Показано, что предварительное ультразвуковое деформирование поверхности пластины ведет к дополнительному возрастанию глубины зоны ее последующей лазерной закалки.
\end{abstract}

Введение. К настоящему времени проведены многочисленные экспериментальные и теоретические исследования процессов, протекающих в поверхностных слоях металлов при кратковременном воздействии на них лазерного излучения, и получены результаты, имеющие важное фундаментальное и прикладное значение [1-4]. Вместе с тем использование этих результатов в применении к лазерной термообработке поверхности металлических пластин в инженерной практике не всегда оказывается успешным. Одной из основных причин этого является отсутствие простого аналитического соотношения, связывающего геометрические размеры зон лазерной термообработки с параметрами лазерного воздействия, теплофизическими характеристиками материала пластин и их толщиной в явном виде.

В соответствии с этим цель данной работы состояла в выводе такого аналитического соотношения на основе собственных экспериментальных исследований и в дополнительном изучении возможностей совмещенного лазерно-ультразвукового воздействия в процессах локального термомеханического упрочнения поверхности металлических пластин.

Методика эксперимента. В качестве образцов нами использовались пластины из стали 40X в исходном отожженном состоянии. Толщина пластин варьировалась от 1 до 7 мм. Для уменьшения коэффициента отражения лазерного излучения поверхность пластин покрывалась 40 мкм слоем черной типографской краски.

Лазерная обработка поверхности пластин осуществлялась непрерывным излучением твердотельного YAG:Nd-лазера ЛТН-103 (длина волны излучения 1.06 мкм). Излучение мощностью 135 и 145 Bm с помощью оптической системы СОК-1 фокусировалось в пятно диаметром 1 мм. Скорость перемещения луча по поверхности пластин составляла 4 мм/c.

При совмещенной лазерно-ультразвуковой обработке поверхности пластин предварительное пластическое деформирование поверхности осуществлялось путем ввода в нее ультразвуковых колебаний через конусообразный концентратор полуволновой длины, который крепился к торцу подключенного к выходу ультразвукового генератора УЗГ1-1 магнитострикционного преобразователя ПМС1-1 и поджимался к поверхности вблизи пятна фокусировки лазерного излучения с усилием $50 \mathrm{H}$. Частота ультразвуковых колебаний составляла $22 \kappa Г u$, амплитуда до 45 мкм, мощность - до $1 \kappa B m$.

Схемы лазерной и лазерно-ультразвуковой обработок поверхности пластин приведены на рис. 1.

Геометрические параметры, микромеханические характеристики и структурно-фазовый состав формирующихся при лазерной и лазерно-ультразвуковой обработках зон исследовались с применением методов металлографии, микродюриметрии и рентгеновского фазового анализа. 
Для травления поперечных шлифов образцов использовался 4 \% раствор азотной кислоты в этиловом спирте. Металлографический анализ структур осуществлялся на оптическом микроскопе Neophot-30. Микротвердость измерялась на приборе ПМТ-3 при нагрузке $0.98 H$. Запись дифрактограмм обработанных поверхностей производилась на дифрактометре Дрон-3 с использованием $K_{\alpha}$-излучения кобальта. При этом содержание остаточного аустенита определялось методом гомологических пар линий $(110)_{\alpha}$ и $(111)_{\gamma}$.

Экспериментальные результаты и их анализ. На рис. 2-4 приведены распределения микротвердости $H_{0.98}$ по глубине $z$ в пластинах толщиной 2 и 4 мм, поверхности которых подвергнуты лазерной обработке, и зависимости содержания остаточного аустенита $A_{\text {ocm }}$ в поверхностных слоях зон лазерной закалки и глубины $z_{3}$ самих этих зон от толщины $h$ пластин соответственно. Анализ представленных результатов показывает, что на процесс лазерной закалки оказывают влияние не только параметры лазерного воздействия (плотность поглощенной мощности излучения и время воздействия) и теплофизические характеристики материала (теплопроводность и температуропроводность), но и геометрические размеры пластин (в частности толщина).

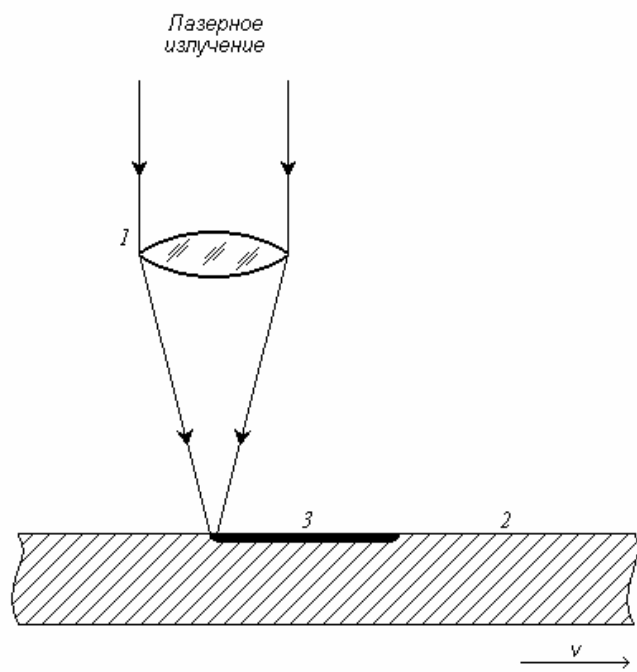

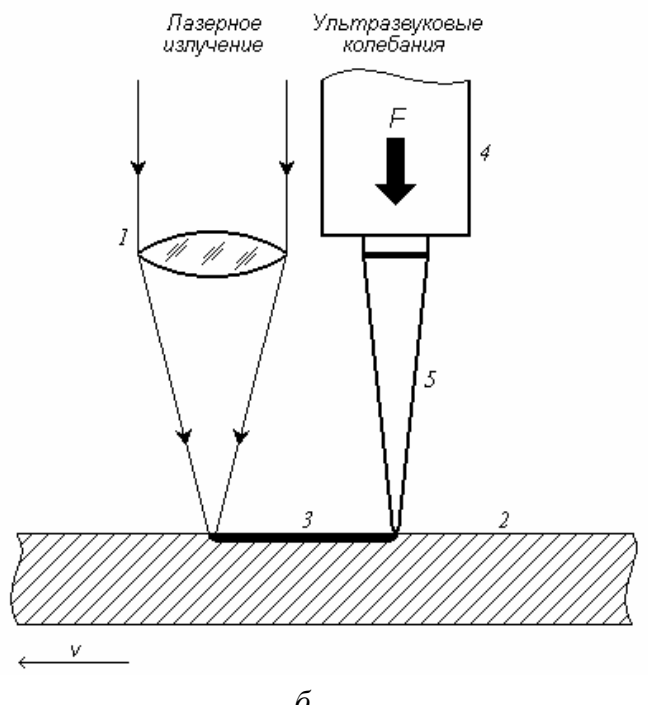

$\sigma$

Р и с. 1. Схемы лазерной $(a)$ и лазерно-ультразвуковой (б) обработок поверхности пластин: 1 - объектив оптической системы, фокусирующей лазерное излучение; 2 - пластина; 3 - зоны лазерной (a) и лазерно-ультразвуковой (б) обработок; 4 - магнитострикционный преобразователь;

5 - конусообразный концентратор полуволновой длины

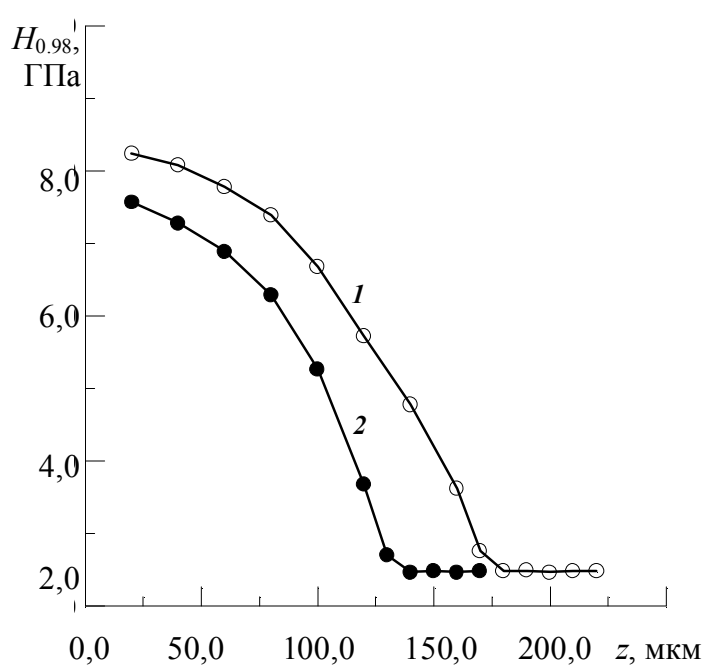

Р и с. 2. Распределения микротвердости $H_{0.98}$ по глубине $z$ зон лазерной закалки поверхности пластин толщиной 2 мм (1) и 4 мм (2):

$$
P=145 \mathrm{Bm}
$$

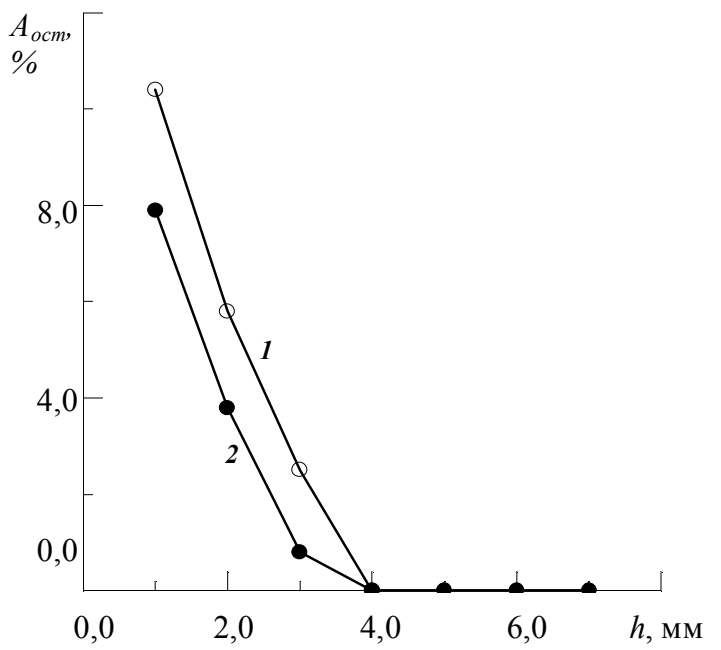

Р и с. 3. Зависимости содержания остаточного аустенита $A_{\text {ocm }}$ в поверхностных слоях зон лазерной закалки пластин от их толщины $h$ :

$$
P: 1-145,2-135 \mathrm{Bm}
$$


Для оценки степени влияния толщины пластин на формирование зон лазерной закалки нами использованы модели полубесконечной среды [2], тонкой пластины [3] и промежуточная модель [4].

В модели полубесконечной среды [2] имеем

$$
T\left(z, t=\frac{d}{v}\right)=\frac{4 P \gamma(\chi)(1-R)}{\pi d^{2} \lambda}\left[\frac{2 d}{\sqrt{\pi}}\left(\frac{a}{d v}\right)^{0.4}-z\right],
$$

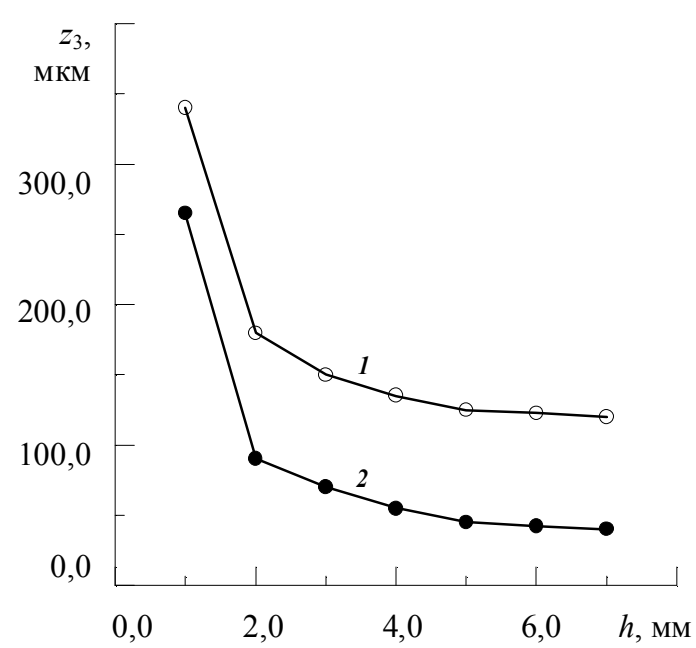

Р и с. 4. Зависимости глубины $z_{3}$ зон лазерной закалки поверхности пластин от их толщины $h$ : $P: 1-145,2-135 \mathrm{Bm}$ где $P=135$ или $145 \mathrm{Bm}$ - мощность лазерного излучения; $d=1$ мм - диаметр пятна фокусировки; $v=4$ мм/c - скорость перемещения лазерного луча по поверхности пластины; $R \approx 0.2$ - коэффициент отражения лазерного излучения поверхностью пластины, покрытой черной типографской краской; $\lambda=26$ $B m / м \cdot г р а д$ и $a=7 \cdot 10^{-6} \mathrm{M}^{2} / c-$ коэффициенты теплопроводности и температуропроводности стали $40 \mathrm{X}$ соответственно; для $\chi=\frac{d v}{4 a}=0.143 \gamma(\chi) \approx 0.1$ - поправочный коэффициент, который совместно с показателем степени $0.4 \mathrm{y}\left(\frac{a}{d v}\right)$ учитывает влияние трехмерности в приведенном решении уравнения теплопроводности; $t=\frac{d}{v}=0.25 \mathrm{c}$ - время лазерного воздействия; $z$ - текущая координата глубины ( $z=0$ соответствует облучаемой поверхности пластины, $z=h$ - ее тыльной стороне).

В модели тонкой пластины [3]-

$$
T\left(z, t=\frac{d}{v}\right)=\frac{4 P \gamma(\chi)(1-R)}{\pi d^{2} \lambda}\left\{\frac{a d}{v h}+h\left[\frac{3 z^{2}-h^{2}}{6 h^{2}}-\frac{2}{\pi^{2}} \sum_{n=1}^{\infty} \frac{(-1)^{n}}{n^{2}} \exp \left(-\frac{n^{2} \pi^{2} a^{2} d^{2}}{v^{2} h^{4}}\right) \cos \left(\frac{n \pi z}{h}\right)\right]\right\},
$$

где $z=h$ соответствует облучаемой поверхности пластины, $z=0$ - ее тыльной стороне.

В промежуточной модели [4]-

$$
\begin{gathered}
T\left(z=0, t=\frac{d}{v}\right)=\frac{8 P \gamma(\chi)(1-R)}{\pi \sqrt{\pi} d \lambda}\left(\frac{a}{d v}\right)^{0.4} ; \\
T\left(z=h, t=\frac{d}{v}\right)=\frac{8 P \gamma(\chi)(1-R)}{\pi \sqrt{\pi} d \lambda}\left(\frac{a}{d v}\right)^{0.4} \exp \left(-h \sqrt{\frac{v}{2 a d}}\right) .
\end{gathered}
$$

Здесь $z=0$ соответствует облучаемой поверхности пластины, $z=h$ - ее тыльной стороне.

Результаты расчета по формулам (1)-(4) температур облучаемой поверхности пластины и ее тыльной стороны в зависимости от толщины пластины приведены на рис. 5. Анализ полученных результатов расчета показывает, что ни одна из использованных моделей не является универсальной. Вследствие этого для адекватного описания экспериментальных результатов за основу нами была выбрана модель полубесконечной среды и эмпирически определена поправка, которую следует ввести в выражение (1). Учет поправки преобразует выражение (1) к виду

$$
T\left(z, t=\frac{d}{v}\right)=\frac{4 P \gamma(\chi)(1-R)}{\pi d^{2} \lambda}\left[\frac{2 d}{\sqrt{\pi}}\left(\frac{a}{d v}\right)^{0.4}\left(1+\frac{a d}{2 \pi \sqrt{\pi} v h^{2}}\right)-z\right],
$$

из которого следует, что глубину зоны лазерной закалки можно прогнозировать, используя выражение

$$
z_{3}=\frac{\pi d^{2} \lambda}{4 P \gamma(\chi)(1-R)}\left[\frac{8 P \gamma(\chi)(1-R)}{\pi \sqrt{\pi} d \lambda}\left(\frac{a}{d v}\right)^{0.4}\left(1+\frac{a d}{2 \pi \sqrt{\pi} v h^{2}}\right)-A_{c 1}\right],
$$


где $A_{c 1}$ - температура инструментального начала фазового $\alpha$ - $\gamma$-превращения в стали $40 \mathrm{X}$ при ее быстром нагреве [2].

Результаты расчета по формулам (5) и (6) температур облучаемой поверхности пластины и ее тыльной стороны, а также глубины зоны лазерной закалки в зависимости от толщины пластины приведены на рис. 6. Здесь же представлены экспериментальные значения формируемых глубин зон лазерной закалки в пластинах различной толщины. Видно, что результаты расчета хорошо согласуются с экспериментальными данными. Это указывает на то, что выведенное нами эмпирическое аналитическое соотношение (6) может быть эффективно использовано в инженерной практике при выборе параметров лазерного воздействия для формирования в металлических пластинах зон лазерной закалки с наперед заданной глубиной.
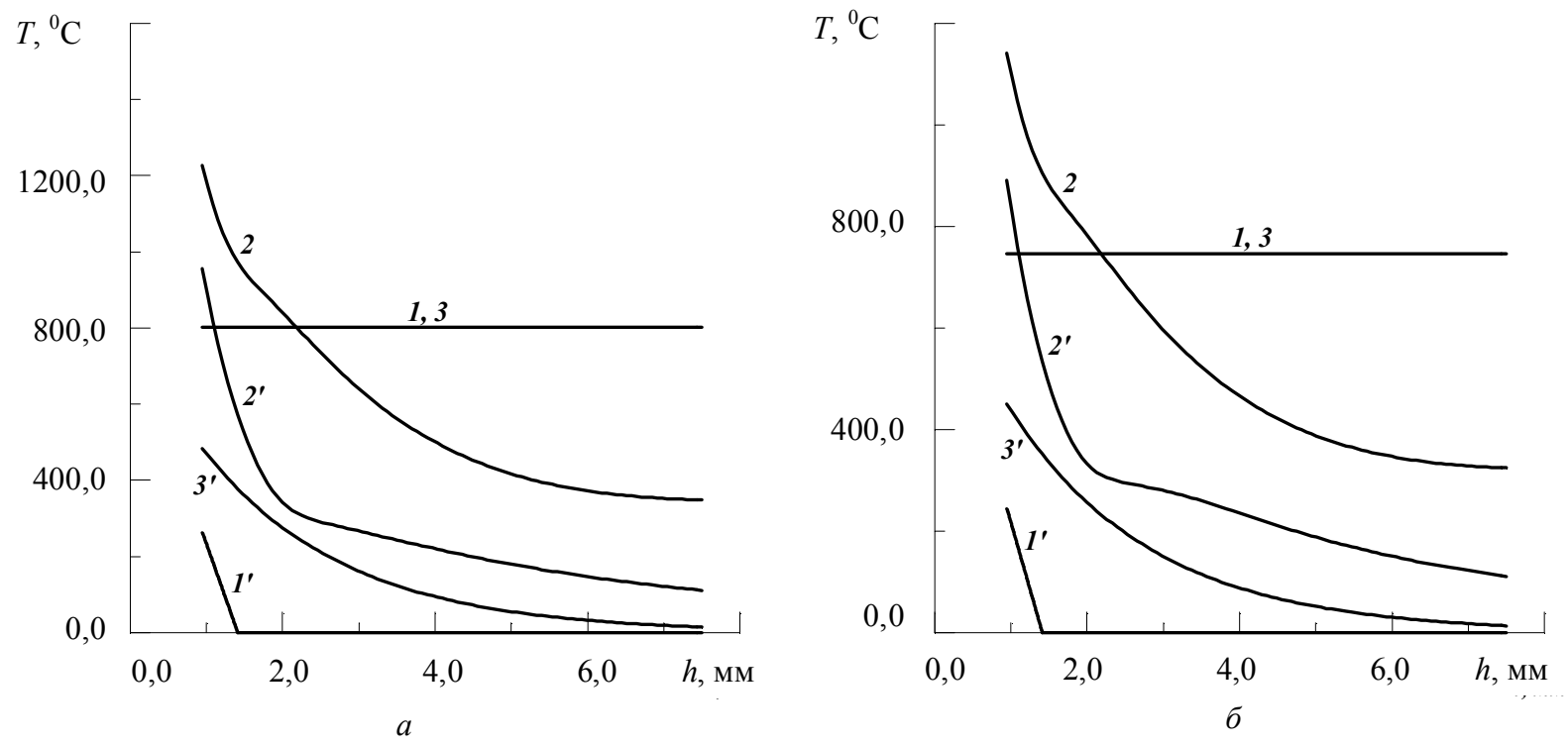

Р и с. 5. Зависимости расчетных температур $T$ облучаемой поверхности $(1,2,3)$ и тыльной стороны $\left(1^{\prime}, 2^{\prime}, 3^{\prime}\right)$ пластин от их толщины $h$ для моделей полубесконечной среды $\left(1,1^{\prime}\right)$, тонкой пластины $\left(2,2^{\prime}\right)$ и промежуточной $(3,3): P, B m: a-145, \sigma-135$

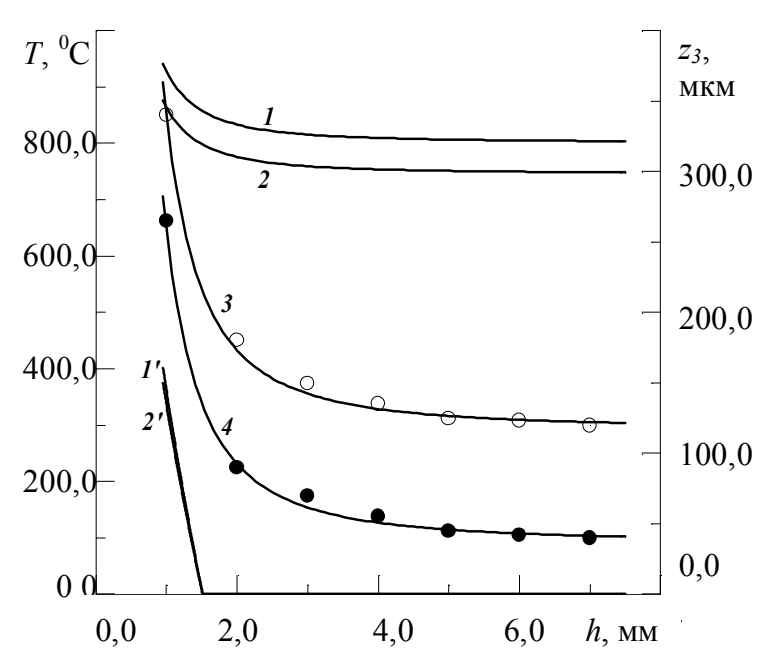

Р и с. 6. Зависимости рассчитанных по формулам (5) и (6) температур $T$ облучаемой поверхности (1, $2)$ и тыльной стороны $\left(1^{\prime}, 2^{\prime}\right)$ пластин и глубины $z_{3}$ зон лазерной закалки поверхности пластин $(3,4)$ от их толщины $h: P, B m: 1,1^{\prime}, 3-145 ; 2,2$ ', 4-135:

Светлые и темные точки - экспериментальные данные из рис. 4

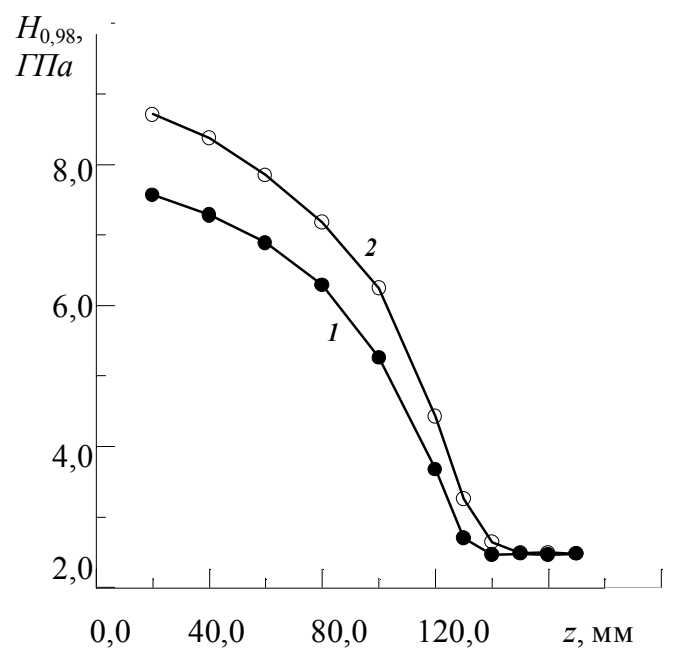

Р и с. 7. Распределения микротвердости $H_{0.98}$ по глубине $z$ зон лазерного (1) и лазерноультразвукового (2) упрочнения поверхности пластины толщиной 4 мм:

$$
P=145 \mathrm{Bm}
$$

На рис. 7 приведены сопоставительные результаты лазерного и лазерно-ультразвукового упрочнения поверхности металлической пластины толщиной 4 мм. Видно, что предваритель- 
ное ультразвуковое деформирование поверхности пластины ведет к дополнительному возрастанию на 15 мкм глубины зоны ее последующей лазерной закалки. В соответствии с развитой в [2] теорией последнее обусловлено уменьшением в зоне пластической деформации температуры $A_{c 1}$ с $\sim 733$ до $\sim 724^{\circ} \mathrm{C}$.

Заключение. Таким образом, в результате теоретического анализа экспериментальных зависимостей получено эмпирическое аналитическое выражение, отражающее хорошо согласующееся с экспериментом влияние на глубину зоны закалки поверхности пластины как параметров лазерного воздействия и теплофизических характеристик ее материала, так и толщины пластины. Это позволяет надеяться на эффективное использование данного выражения в инженерной практике.

Показано, что совмещение предварительного ультразвукового деформирования поверхности пластины с ее последующей лазерной закалкой является эффективным способом увеличения толщины упрочненного слоя, в основе которого лежит снижение температуры начала фазового $\alpha$ - $\gamma$-превращения в пластически деформированной стали.

\section{БИБЛИОГРАФИЧЕСКИЙ СПИСОК}

1. Григорьяни А.Г., Сафонов А.Н. Основы лазерного термоупрочнения сплавов. М.: Высш. шк., 1988. 159 с.

2. Гуреев Д.М., Ямщиков С.В. Основы физики лазеров и лазерной обработки материалов. Самара: СамГУ, 2001. $392 \mathrm{c}$.

3. Прохоров А.М., Конов В.И., Урсу И., Михэилеску И.Н. Взаимодействие лазерного излучения с металлами. М.: Наука, 1988. 537 с.

4. Жаткин С.С. Особенности динамики нагрева, структурных изменений и релаксационных процессов в металлах при импульсном лазерном воздействии / Автореферат дисс... канд. физ.-мат. наук. Самара: СамГТУ, 1996. 17 с. 